\title{
Acta Diabetologica is 50 and well: long live Acta!
}

\author{
Massimo Porta
}

Received: 16 December 2013/Accepted: 23 January 2014/Published online: 29 January 2014

(C) Springer-Verlag Italia 2014

Acta Diabetologica has gone through a number of important changes this past year. First, and for the better, its Impact Factor enjoyed an impressive rise. Second, more worryingly, its authoritative and well-experienced Editorsin-Chief stepped down after achieving this rewarding result. Fortunately, Professors Guido Pozza and Renato Lauro, to whom heartfelt thanks are due for their steady guidance of the journal, will continue to make their experience available as Founding Editor and Honorary Editor, respectively. Thirdly, having been established in 1964 as Acta Diabetologica Latina, the journal celebrates its 50th birthday and is the oldest active diabetes journal in Europe.

It is with such awesome thoughts in mind that this new Editor-in-Chief took charge last June. His predecessors led Acta Diabetologica to first league among Endocrine and Metabolism publications and entrusted him with the ability to continue their good work. Some of the action to this effect will go under the sign of continuity and some will have to take note of changing times. Rigorous selection of the manuscripts received by the Editorial Office will continue to be enforced, jointly with the two long-serving Managing Editors, Professors Massimo Federici and Antonio Secchi, and with old and new members of the Editorial and Advisory Boards. We shall have to be tough and maintain the current $80 \%$ rejection rate. However, more importantly, we shall strive to be as fair as possible. This Editorial Board believes that quality is more important than quantity and that publishing good articles is better than publishing few articles. No good papers left behind should be our motto, probably not shared by all those

M. Porta $(\bowtie)$

Department of Medical Sciences, University of Turin, Turin, Italy

e-mail: massimo.porta@unito.it authors who will see their submissions rejected. Alas, journal Editors do not make many friends!

But a good Impact Factor is not all there is to life of journals, editors, authors, and publishers. More important is the choice of an editorial line that will do its modest share to genuinely stimulate original research in the field of human diabetes and metabolism. This may sound matter of fact but a number of signals emerging from the world of science should be taken very seriously indeed. Karl Popper based his view of scientific progress on the concept of "Fälschungsmöglichkeit" or empirical falsification of data, meaning that current wisdom can constantly be proven false when newer concepts are applied to previous knowledge and suggesting that science tends to evolve by correcting itself [1]. But in Popper's time, scientific research was still an educated hobby for affluent gentlemen. In his "Gattopardo," Giuseppe Tomasi di Lampedusa provides us with the memorable description of a Sicilian prince who, among other nightly enjoyments, could afford a private observatory to explore the terse skies above his land and even discover one or two new celestial objects, which he duly communicated to the learned societies of his day [2]. Until perhaps the first half of the twentieth century, many new things could be described with a lot of amateurial dedication, sharp intelligence, and relatively affordable means. Today, research is a profession, costly, competitive and requiring complex technical skills, deep knowledge and full-time dedication. Rewards derive mostly from the dissemination of one's own results, and in today's "publish or perish" environment, powerful forces tend to derail research(ers) from pursuing the straight line of advancement of knowledge for the ultimate benefit of mankind. Pressure to publish is sometimes stronger than prudence.

Staff at a leading biotech firm were able to replicate the results of only 6 out of 53 landmark papers in cancer [3] 
and those at another large pharmaceutical firm could only reproduce a quarter of 67 "seminal" studies [4] in a trend that increasingly appears to apply to most fields of research. There are many possible explanations for failure to reproduce the Results of a given publication, and they do not necessarily involve misconduct. Sometimes, the truth, only the truth but not all the truth, is detailed in Materials and Methods. Experimental conditions may change in subtle ways from one laboratory to another, and inexplicable variables can be summed up in terms of technicians' "green thumb." Nonetheless, pressure to publish may lead to divulgate results before they are solidly validated. Results will be published more easily if they describe positive findings. Negative results find it increasingly harder to make it to the presses: according to a survey, the rate of published negative results across science dropped from 30 to $14 \%$ between 1990 and 2007 [5]. This way, publication bias leads to consolidate "findings" and prevents dissemination of negative results, leading unaware researchers to beat the same sterile tracks until, eventually, a "positive" result is found (by convention, 1 out of 20 results is significant by chance). Will anybody who did not see their unpublished negative observations superseded by somebody else's "findings," please raise their hands?

The problem is compounded by the practice of "salami publishing," the art of producing as many papers as possible by "slicing" slightly different sets of results out of the same database. Multiple publications may be justified when rationale and results are genuinely different and cannot sit together in a balanced manuscript. There are illustrious examples in the literature. However, publishing similar results from the same source of data or, worse, publishing them twice adds to drifting science away from the straight line.

One pillar of science ability to correct itself is supposed to rest upon peer review. The opportunity is taken here to thank those who have reviewed and will continue to do so for Acta Diabetologica and, more aptly, to apologize for distracting them from their own work. Often peers are overstretched and provide their services out of goodwill in their certainly not copious free time. As a result, to the best of their performance, they may fail to spot important weaknesses in a paper. In a notorious survey, the Editor of the British Medical Journal had a manuscript, deliberately modified to include 8 major flaws, assessed by 221 reviewers. On average, they managed to spot 2 flaws and many reported none [6].

If these are pitfalls with science in general, research in diabetes has its own share of problems. A rough search of Medline produced 352,834 publications containing the words "Diabetes" or "Diabetic" in their title or abstract between 1975 and 2012, the number rising almost exponentially year on year. Despite such skyrocketing production, we remain unable to answer basic questions. What causes the absolute or relative defect of insulin action at the basis of diabetes? With diagnostic criteria continuously evolving and being put under discussion, do we have a clear idea of what constitutes diabetes? Insulin and other glucose-lowering agents save lives from acute complications but more often than not fail to achieve desired glycemic targets. What is the pathogenesis of vascular complications? If diabetes is an independent cardiovascular risk factor, then why does intensive glycemic control not reduce cardiovascular outcomes [7]? Old studies of identical twins suggest a strong genetic background and yet, so far, we have failed to identify robust genetic predictors. The list could go on, reflecting poorly on what we can do for our patients, their health, and their everyday life.

In his "Structure of Scientific Revolutions" [8], Thomas Kuhn proposed that science does not develop linearly through the accumulation of new knowledge but rather by alternating paradigmatic periods with revolutionary phases. During "normal" periods, science adheres to the dominating paradigm, which provides scientists with "puzzles" to solve and with the tools to solve them. As more and more "anomalies" emerge, puzzles become increasingly difficult to solve, science enters a crisis, and a revolution is necessary to substitute the old with a new, incommensurable, paradigm. Think of Ptolemy's universe and the subsequent Copernican revolution. Arguably, we can place the last revolution in diabetes research with Oskar Minkowski's discovery of pancreatic diabetes in 1889 [9]. Before that, diabetes was considered a renal disease and treated accordingly. Now, we treat it as a disease of the endocrine pancreas but more and more anomalies emerge. Is a new revolution unavoidable?

Scientific and medical journals have their share of responsibility in the maintenance of the paradigmatic status quo. Publishing is their bread and butter but their eating habits should be more adventurous. They thrive on a diet of "me too" manuscripts and are reluctant to put received wisdom under discussion. History teaches us that milestones in diabetes research were set by experts in other disciplines, such as Minkowski himself [9], Frederick Banting [10], Auguste Loubatières [11], Rosalyn Yalow [12], Salman Rachbar [13] to quote a few. In some notable cases, their seminal papers were rejected when first submitted [11]. On the other hand, diabetologists' contribution in the pre-insulin era includes such paradigmatic concepts as "education," intended as a quasi-ascetic patient adherence to prescriptions, and its corollary "starvation diets"a self-explanatory term- [14]. "Intensive metabolic control" emerged many years later. The resulting mix of science and moral judgement resonates to this date in the basic approach of many health operators to patients who are not "compliant" or "adherent" to their satisfaction. Compliant 
with what is not entirely clear, as newer classifications, diagnostic criteria, guidelines, recommendations, and opinions are issued regularly. It is an Editor's highest hope, and thankless job, that sifting through arriving manuscripts will reveal some genuine gold straws.

What can journals do to help put things right, or at least not let them go too wrong, in this kind of environment? Keeping guard on quality, one should be more open to negative data, particularly when they fail to confirm received wisdom. At the same time, truly important new findings should be spotted for what they are. Descriptions of methods should be as detailed as possible and online appendixes are a helpful option these days. Software can spot copycats, either different authors in the case of plagiarism or same authors in the case of data duplication, and strict guidelines detail what constitutes breach of publication ethics and force Editors to inflict Retractions, Notices of Redundant Publication and other sanctions on misbehavers [15].

Finally, a journal success depends on professionalism, expertise, and financial independence. The former is provided by Springer's superb editorial staff assisting with the day-to-day running of Acta Diabetologica. They have allowed us to progressively reduce handling times: in January-September 2013, it took 16 days to reject a manuscript and 71 days to finally accept one. Meanwhile, a series of double issues was printed to reduce the backlog of online-only publications to a physiological level. Expertise will be hopefully enlarged by including more scientific bodies in the Editorial Board. As of this year, reputable representatives of the Italian societies of Internal Medicine and Endocrinology will join their colleagues from the sister Italian societies of Diabetes. In the future, as growth in international authorship and readership will further consolidate, a more global perspective will have to be adopted. Last, consistent with the requests placed on our authors, a potential conflict of interest declaration is in order. Acta Diabetologica Latina was founded 50 years ago with the financial help of Hoechst Pharma and the journal continues to be supported by Sanofi. This never translated in the slightest interference on the editorial line, nor would the past Editors have tolerated one. To the contrary, it shielded Acta Diabetologica from financial pressure to publish commercially relevant results. It will be the job of this Editorial Board to ensure a reliable, independent service to the large community of professionals who genuinely continue to be interested in the advancement of diabetes research and patient care.

Conflict of interest Massimo Porta declares he has no conflict of interest.

Human and animal rights disclosure This article does not contain any studies with human or animal subjects performed by the author.

\section{References}

1. Popper KR (2004) Conjectures and refutations: the growth of scientific knowledge (reprinted edn). Routledge, London, ISBN: 0-415-28594-1

2. Tomasi di Lampedusa G (1958) Il Gattopardo. Feltrinelli, Milan

3. Begley CG, Ellis LM (2012) Drug development: raise standards for preclinical cancer research. Nature 483:531-533

4. Prinz F, Schlange T, Asadullah K (2011) Believe it or not: how much can we rely on published data on potential drug targets? Nat Rev Drug Discov 10:712-713

5. Fanelli D (2012) Negative results are disappearing from most disciplines and countries. Scientometrics 90:891-904

6. Godlee F, Gale CR, Martyn CN (1998) Effect on the quality of peer review of blinding reviewers and asking them to sign their reports. A randomized controlled trial. JAMA 280:237-240

7. Boussageon R, Bejan-Angoulvant T, Saadatian-Elahi M, Lafont S, Bergeonneau C, Kassaï B, Erpeldinger S, Wright JM, Gueyffier F, Cornu C (2011) Effect of intensive glucose lowering treatment on all cause mortality, cardiovascular death, and microvascular events in type 2 diabetes: meta-analysis of randomised controlled trials. BMJ 343:d4169

8. Kuhn TS (1962) The structure of scientific revolutions. The University of Chicago Press, Chicago

9. Mering JV, Minkowsky O (1899) Diabetes mellitus nach Pankreasextirpation. Centralblatt fur Klinische Medizin 23:393

10. Banting FG, Best CH, Collip JB, Campbell WR, Fletcher AA (1922) Pancreatic extracts in the treatment of $X$ diabetes mellitus: preliminary report. Can Med Assoc J 12:141-146

11. Loubatières A (1944) Analyse du mécanisme de l'action hypoglycémiante du p-amino-benzène-sulfamido-alkilthiodiazols. C R Soc Biol (Paris) 183:830

12. Kahn CR, Roth J (2004) Berson, Yalow, and the JCI: the agony and the ecstasy. J Clin Invest 114:1051-1054

13. Rahbar S, Blumenfeld O, Ranney HM (1969) Studies of an unusual haemoglobin in patients with diabetes mellitus. Biochem Biophys Res Commun 36:838-843

14. Mazur A (2011) Why were "starvation diets" promoted for diabetes in the pre-insulin period? Nutr J 10:23-32

15. http://publicationethics.org/ 